\title{
¿POR QUÉ EL MINISTERIO DE TRABAJO EN ESPAÑA SE CREÓ EN EL AÑO 1920? UNA APROXIMACIÓN
}

\author{
Montserrat Llonch Casanovas \\ Profesora Agregada de la Facultat d’Economia i Empresa, Unitat d’Història Econòmica \\ Universitat Autònoma de Barcelona
}

\begin{abstract}
El artículo pretende una aproximación a la creación del Ministerio de Trabajo en España en 1920. Se plantea la oportunidad de esta nueva institución en la coyuntura de posguerra, así como la contemporaneidad respecto a otros países europeos. Se constata una cronología análoga respectos a los países europeos occidentales y una motivación similar, en el marco de la fundación de la OIT. Pese a las analogías, el caso español destaca por la simultaneidad de la crisis del régimen político, la crisis económica y un clima de radicalidad y violencia social exacerbado. La oportunidad de la creación del Ministerio de Trabajo en 1920 no presupone ninguna valoración comparativa de su gestión y funcionamiento en materia laboral.
\end{abstract}

The article seeks an approximation to the creation of the Ministry of Labor in Spain in 1920. The opportunity of this new institution in the post-war situation is considered, as well as its contemporaneity with respect to other European countries. A similar chronology is found with respect to Western European countries and a similar motivation, within the framework of the founding of the ILO. Despite the analogies, the Spanish case stands out for the simultaneity of the crisis of the political regime, the economic crisis and a climate of radicalism and exacerbated social violence. The timing of the creation of the Ministry of Labor in 1920 does not presuppose any comparative assessment of its management and operation in labor matters.

Palabras clave: historia instituciones económicas, trabajo, OIT, España, Europa de entreguerras.

Keywords: history of economic institutions, work, ILO, Spain, interwar Europe

IUSLabor 1/2021, ISSN 1699-2938, p. 164-187

DOI. 10.31009/IUSLabor.2021.i01.07

Fecha envío: 30.10.2020 | Fecha aceptación: 15.3.2021 


\section{Sumario}

1. Introducción

2. El despertar tras la Gran Guerra

3. Malestar social como gran escollo de la posguerra europea

4. La creación de los ministerios de trabajo en Europa en la posguerra europea

5. El entorno particular del caso español

6. Oportunidad en la creación del Ministerio de Trabajo en España

7. Conclusiones

8. Bibliografía 


\section{Introducción}

Los estudios de las instituciones públicas son imprescindibles para analizar la complejidad de la sociedad contemporánea, sus transformaciones, problemas y eventuales mejoras ${ }^{1}$. En particular, el análisis histórico de las instituciones económicas es relevante desde una perspectiva dinámica, para entender su proceso de gestación, creación y desarrollo, a fin de evaluar su función en un contexto político y socioeconómico determinado.

Las instituciones políticas públicas oficiales no son organismos estáticos. Dichas instituciones son fruto de la sociedad y de la estructura jurídica y política de un país en un tiempo histórico determinado. Por esta razón, las instituciones requieren de cierto grado de adaptabilidad a los nuevos desafíos y problemas que se van desarrollando en la sociedad, en base a creación de nuevas instituciones o la reforma de instituciones ya existentes.

Las instituciones de la administración pública son jerárquicas con vertebración funcional y territorial que se han ido configurando históricamente con diferencias en virtud de las trayectorias de cada estado. ${ }^{2}$ Cada nivel jerárquico de una institución de la administración pública contaba y cuenta con funciones y atribuciones diferenciadas, lo que determina su alcance. A modo de ejemplo, un organismo autónomo (como el Instituto de Reformas Sociales creado en 1903) no contaba con las mismas atribuciones que un ministerio (el Ministerio de Trabajo creado en 1920), que podía regular en voz propia y contar con un presupuesto para articular políticas públicas de su ámbito de actuación.

Los cambios en la configuración de la administración pública de alto nivel no fueron excepcionales durante la Restauración (1874-1931), ya que en el año 1886 se crearon diversos ministerios (el Ministerio de Instrucción Pública, Ciencias, Letras y Bellas Artes; y el Ministerio de Obras Públicas, Agricultura, Industria y Comercio) y tuvo lugar la creación de los primeros organismos autónomos (el Instituto de Reformas Sociales en el año 1903 y Nacional de Previsión en 1908). Así pues, la creación del Ministerio de Trabajo en el año 1920 no fue un hecho insólito en el panorama administrativo público español.

\footnotetext{
${ }^{1}$ VERGARA, Jorge Iván "Teorías conservadoras y teorías críticas con las instituciones sociales", Revista de Ciencias Sociales, 11, 2001, p. 139. A su vez, es posible analizar las instituciones (en su acepción amplia) no sólo como contingente de prácticas humanas sino como actores de representación social que tienen dimensión histórica. DOUGLAS, Mary, Cómo piensan las instituciones, Madrid, Alianza Universidad, 1996.

${ }^{2}$ Sobre el caso español, véase BAENA DEL ALCÁZAR, Mariano, "El proceso histórico de formación de la administración central actual" en Curso de Ciencia de la Administración, Madrid, Tecnos, 1996, p. 170192.
} 
En este artículo nos preguntamos las razones que explican la creación del Ministerio de Trabajo en España en el año 1920 desde la perspectiva de la historia económica, política y social. En particular, nos interesa situar el nuevo organismo ministerial español en el contexto internacional, a fin de entender su eventual oportunidad para atender a los problemas referentes al mercado de trabajo en España. Para responder a este objetivo, en primer lugar, haremos un breve repaso a las consecuencias de la Primera Guerra Mundial en Europa, poniendo especial énfasis en el malestar social que siguió a la contienda y sus consecuencias, como la creación de la Organización Internacional del Trabajo. A continuación, nos situaremos en el contexto español a fin de concretar sus particularidades y la oportunidad de creación del Ministerio de Trabajo. Finalmente, se indicarán unas breves conclusiones.

\section{El despertar tras la Gran Guerra}

Hay cierto consenso en la disciplina de la historia económica sobre que el siglo XIX económico finalizó con el estallido de la Gran Guerra. Esta afirmación se sustenta en la constatación de que la conflagración interrumpió la primera globalización (1870-1913), una etapa caracterizada por una gran expansión del comercio internacional y de la movilidad de los factores de producción entre países (las migraciones internacionales y la inversión exterior). ${ }^{3}$ La primera globalización supuso la articulación de un mercado mundial de productos y de factores de producción. ${ }^{4}$

En el año 1914, la primera globalización quedó interrumpida y se abrió paso a cuatro años de una cruenta guerra de desgaste. La Gran Guerra afectó gravemente las relaciones políticas y económicas mantenidas entre países. Por razones militares y estratégicas, quedó interrumpido el comercio entre países que formaban parte de los dos bloques de países enfrentados, mientras que el comercio entre los países europeos industriales y el resto del mundo quedó desarticulado. A esta circunstancia, cabe añadir, los graves

\footnotetext{
${ }^{3}$ Dani Rodrik plantea que la primera globalización obedeció a razones tecnológicas y económicas (nuevas tecnologías de transporte y comunicación que permitieron reducir los costes de intercambio, la reducción de las restricciones y la anulación de las prohibiciones explícitas al comercio internacional; la adopción generalizada del patrón oro que facilitó la movilidad del capital). Pero la perspectiva analítica de Rodrik señala la conveniencia de integrar las variables institucionales (como la convergencia del sistema de creencias entre los principales dirigentes económicos del período; y el Imperialismo como mecanismo para imponer reglas de comercio en base al despliegue del poder político y militar de los principales países a fin de alinear al resto del mundo). RODRIK, Dani, The Globalization Paradox-Democracy and the Future of the World Economy, New York, W.W. Norton \& Company, 2011, p. 17 y ss.

${ }^{4}$ La evidencia más sobresaliente de la integración de los mercados fue una mayor convergencia mundial de los precios de los factores de producción y de los principales productos comercializados, que ha sido ratificada en la economía atlántica que conectaba Europa con América. O'ROURKE, Kevin H; WILLIAMSON, Jeffrey G., Globalization and History. The evolution of a Nineteenth-Century Atlantic Economy, Cambridge \& London, The MIT Press, 1999.
} 
problemas en el transporte marítimo (en parte causados por la guerra submarina) y la afectación de las comunicaciones que acabaron alterando gravemente y reduciendo los intercambios y las migraciones internacionales y los flujos de inversión entre países.

Al estallar la Primera Guerra Mundial, el objetivo de alcanzar la victoria pasó a ser el objetivo principal de los países enfrentados. Para ello, los gobiernos priorizaron las producciones de los sectores estratégicos: armamento, munición, productos químicos, equipos de guerra, suministros a las tropas, entre otros. La focalización estratégica en sectores de bienes de producción modificó la estructura productiva de estos países durante guerra. Los sectores productivos más sacrificados fueron los bienes de consumo. Estos cambios productivos, juntamente con la alteración del transporte y las comunicaciones internacionales, afectaron la provisión de terceros países no industriales, que ya no podían contar con las entradas de productos manufacturados procedentes de países ahora en guerra, situación que aprovecharían nuevos competidores industriales.

Por otro lado, el gasto realizado por los gobiernos beligerantes en aras al esfuerzo bélico rompió con la estabilidad monetaria de preguerra. Bajo el sistema del patrón oro, que funcionó entre 1870 y 1913, los países habían mantenido una gran estabilidad en los tipos de cambios entre monedas. La financiación de los países y el gasto asociado a la guerra rompió el equilibrio del patrón oro.

La guerra supuso un auténtico revulsivo en la intervención de los gobiernos implicados en la contienda por los recursos y población movilizados. A diferencia de conflictos bélicos previos, la implicación de la ciudadanía fue enorme; también lo fueron los sacrificios y el coste de la población durante la contienda. A la elevada mortalidad de la guerra, agravada por la gripe de 1918, los pueblos de las naciones en conflicto padecieron los efectos de la inflación, la escasez de recursos básicos y el caos. ${ }^{5}$

Pero a la guerra se le sumarían las graves consecuencias derivadas de la conflagración. Con el fin de la guerra, se desmembraron los grandes imperios europeos (Imperio alemán -Kaiserreich-, Imperio ruso y el Imperio Austrohúngaro -Habsburgo-), dando lugar a la redefinición de las fronteras en el Centro y Este de Europa y, con ellas, el establecimiento de nuevos estados: Checoslovaquia, Yugoslavia, Hungría, Polonia, Estonia, Letonia, Lituania y Finlandia. De formar parte de grandes imperios, los nuevos estados realizaron

\footnotetext{
${ }^{5}$ Se calcula que la mortalidad por la pandemia de gripe (primavera 1918 a 1920) fue muy elevada, pero su cuantía aún es objeto de diversas estimaciones, aunque muchas fuentes apuntan a que su mortalidad sobrepasó aquella provocada por la Primera Guerra Mundial. MALUQUER DE Motes, Jordi, "El quart cavaller de l'Apocalipsi: Impacte demogràfic de la grip de 1918-1920 a l'Europa Llatina i als països de parla catalana", Butlletí de la Societat Catalana d'Estudis Històrics, 31, 2020, 399-441, concretamente tabla 1, p.400.
} 
un despliegue institucional y pasaron a establecer constituciones democráticas, pese a que su clave de futuro radicaba en Alemania. ${ }^{6}$ La economía de muchos de estos nuevos estados experimentaron cambios substanciales de las relaciones económicas previas, por lo que la articulación de las economías nacionales necesitaba de un proceso de integración de los mercados. Esta intensa transformación política, económica, monetaria y social de estos estados tuvo lugar sin un programa de ayuda y coordinación internacional, en el marco de una gran inestabilidad de la Europa de entreguerras. ${ }^{7}$

Los tratados de paz impusieron elevadas sanciones económicas en concepto de reparaciones de guerra a los países derrotados, entre los que se encontraban la principal economía de Europa: Alemania. La materialización de estas indemnizaciones acabó condicionando la recuperación de la economía europea. ${ }^{8}$ En definitiva, la finalización de la Primera Guerra Mundial abrió paso al período de entreguerras caracterizado por la inestabilidad y la incertidumbre que desembocarán en el crack de 1929 y a la depresión de los años treinta. ${ }^{9}$

\section{Malestar social como gran escollo de la posguerra europea.}

No debe olvidarse que la creación de la Organización Internacional del Trabajo (OIT) fue parte del Tratado de Versalles de 1919 en defensa de una regulación laboral internacional

\footnotetext{
${ }^{6}$ MAZOWER, Mark, La Europa negra. Desde la Gran Guerra hasta la caída del comunismo. Berlin Libros, Valencia, 2017, p. 25.

${ }^{7}$ Un ejemplo de la poca estabilidad económica y social de los nuevos estados fueron los intensos procesos hiperinflacionarios experimentados, además de Alemania durante el otoño de 1923, por las nuevas unidades monetarias de los nuevos países del este, como Austria (1922) y Polonia (1923). FELIU, Gaspar y SUDRIÀ, Carles, Introducció a la història econòmica mundial, València, Universitat de Barcelona y Universitat de Valencia, 2006, p.276-281.

${ }^{8}$ Como testimonio critico de la elaboración del Tratado de Versalles del 28 de junio de 1919 puede verse sus interesantes impresiones recogidas en KEYNES, John Maynard, Las consecuencias económicas de la paz, Barcelona, Crítica, reimpresión. Sobre este período, puede consultarse también ALDCROFT, Derek H., Historia de la economia europea, 1914-1980, Barcelona, Crítica, 1989, p. 74-86 y FELIU y SUDRIÀ, op.cit., p. 276 i ss.

${ }^{9}$ CABRERA, Mercedes; JULIÁ, Santos; MARTÍN ACEÑA, Pablo (Comp.), Europa en crisis: 1919 1939, Madrid, Pablo Iglesias, 1991.
} 
que defendiera la justicia social como garante de una paz universal estable. ${ }^{10}{ }^{11} \mathrm{La}$ composición de la OIT se articuló de manera tripartita, con representación gubernamental, empresarial y sindical. La comisión de su creación estuvo formada por nueve países: Bélgica, Cuba, Checoslovaquia, Francia, Italia, Japón, Polonia, Reino Unido y Estados Unidos. España estuvo presente en la Conferencia de Washington de 1919, como uno de los treinta y nueve miembros de pleno derecho, pero relegada a segunda potencia al no entrar entre los ocho estados de mayor importancia industrial ${ }^{12}$.

La necesidad de articular una regulación internacional en materia laboral encuentra sus raíces en la Asociación Internacional para la Protección Internacional de los Trabajadores (1901) y tiene entre sus razones algunas motivaciones económicas evidentes, como la de limitar la competencia comercial entre países en base a regulaciones laborales nacionales diferenciadas. Entre los años 1858 y 1915, decenas de tratados comerciales bilaterales explicitaban anotaciones concretas a fin de evitar la competencia en materia de regulación laboral $^{13}$. A pesar de las reticencias, las evidencias apuntan a que los países que tuvieron una economía más abierta entre 1890 y 1913 (con un mayor peso del comercio exterior

10 "Whereas the League of Nations has for its object the establishment of universal peace, and such a peace can be established, only i fit based upon social justice.

And whereas conditions of labour exist involving such injustice, hardship and privation to large numbers of people as to produce unrest so great that the peace and harmony of the world are imperilled; and an improvement of those conditions is urgently required : as, for example, by the regulation of the hours of work, including the establishment of a maximum working day and week, the regulation of the labour supply, the prevention of unemployment, the provision of an adequate living wage, the protection of the worker against sickness, disease and injury arising out of his employment, the protection of children, Young persons and women, provision for old age and injury, protection of the interests of workers when employed in countries other than their own, recognition of the principle of freedom of association, the organisation of vocational and technical education and other measures;

Whereas also the failure of any nation to adopt humane conditions of labour is an obstacle in the way of other nations which desire to improve the conditions in their own countries".

Part XIII of the Peace Treaty. Labour, Section I. Organisation of Labour. International Labour Office, "Introduction" The Labour Provisions of the Peace Treaties. Geneva, 1920, p. 1.

${ }^{11}$ El Tratado de Versalles fue adoptado en su totalidad por la Conferencia de la Paz el 28 de junio de 1919. Desde el articulo 387 al articulo 427 de la parte XIII de la Conferencia de Paz tratan sobre la estructura de la OIT y su funcionamiento. Estos artículos pueden consultarse en International Labour Office (1920), op. cit. Es de especial relieve el interés de la OIT para garantizar la participación de las mujeres en la nueva institución, que es explícita en diversos artículos, como los artículos 387 y 395.

12 CUESTA BUSTILLO, Josefina, Las relaciones entre España y la Organización Internacional del Trabajo (1919-1939), Madrid, Consejo Económico y Social, 1994, p. 48-68.

13 ENGERMAN. Stanley L. "The History and Policial Economy of International Labor Standards" en BASO, Kaushik; HORN, Henrik; ROMÁN, Lisa; SHAPIRO, Judith (ed) International Labor Standards. Blackwell Publishing, 2003, p. 63-65. 
respecto al conjunto de la economía del país) se correspondieron con los que disponían de mejores estándares laborales. ${ }^{14}$

No obstante, el contexto histórico ayuda a entender la oportunidad de la fundación de la OIT en el año 1919. El malestar social fue el principal problema de la postguerra europea. Las luchas y protestas de la clase trabajadora se podrían atribuir a tres factores principales: la desigualdad generada por la contienda y las dificultades de recuperación de la economía europea, al poder creciente de las organizaciones sindicales y a la influencia de la revolución rusa en los movimientos de la clase trabajadora.

En primer lugar, cabe tener en cuenta que, con la posguerra llegó la necesidad de recuperar la economía y la vida social, además de hacer frente a la elevada mortalidad, un número copioso e inaudito de inválidos entre la población masculina excombatiente, al paro masivo en una población exhausta por el conflicto.

En segundo lugar, la guerra conllevó un impulso para las organizaciones sindicales en Europa, algunas de las cuales ya estaban sólidamente establecidas previamente. ${ }^{15}$ Durante la Primera Guerra Mundial, el mantenimiento de la disciplina y moral del ejército supuso presiones, concesiones y futuras promesas sensibles por parte de los gobiernos para mejorar las condiciones de los trabajadores. ${ }^{16}$ La necesidad urgente de aumentar la producción durante la contienda para la producción de suministros militares requirió el reconocimiento y concesiones de los sindicatos, que aumentaron su afiliación a partir de 1916 en Gran Bretaña, Francia y Alemania.

Y, en último lugar, la revolución rusa ejerció una enorme influencia en los movimientos de la clase trabajadora, que cuestionaron el modelo de la economía capitalista. Según

\footnotetext{
${ }^{14}$ HUBERMAN, Michael; LEWCHUK, Wayne "European economic integration and the labour compact, 1850-1913", European Review of Economic History, nº 7, 2003, p. 3-4.

${ }^{15}$ El Trade Union Congress pasó de 4,1 a 8,3 millones de miembros entre 1913 y 1918 y sus demandas se radicalizaron. TAYLOR, Andrew J., Trade Unions and Politics. A comparative introduction. London, Macmillan, 1989, p. 4. Además, después del masivo reclutamiento de las trabajadoras asalaridas a raíz de la primera guerra mundial en Gran Bretanya, la afiliación de las trabajadoras aumentó $160 \%$ en la Federación Nacional de Trabajadoras a fin de defender sus derechos laborales según DAVIS, Mary. s.d. An historical introduction to the campaign for equal Pay. TUC \& London Metropolitan University website. http://www.unionhistory.info/equalpay/roaddisplay.php?irn=820 (acceso 11 marzo 2021).

${ }^{16}$ En el caso de Alemania, en plena guerra mundial, el Reichstag aprobó en el año 1916 la ley sobre los comités de trabajadores, por la que fueron prescritas como obligatorias las comisiones de trabajadores y empleados para representar al personal ante el patrono o empresario en cada empresa, lo que supuso un logro para la clase obrera alemana según MÜLLER-JENTSCH, Waltherx "Industrial democracy: Historical development and current challenges", Management Revue, $\mathrm{n}^{\circ}$ 19, vol. 4, 2008, p. 260-273. Los comités de trabajadores de empresa acabaron configurando una parte nuclear del modelo cooperativo de relaciones laborales de la empresa alemana.
} 
algunos autores ${ }^{17}$, la importancia de los acontecimientos sociales fue distinta en función de la relativa debilidad de las economías y de los gobiernos que emergieron en la posguerra. A mayor desestabilización económica y fragilidad política del país en cuestión, la radicalidad de las respuestas laborales fue superior. En muchos países, se puso en relieve el fracaso de las viejas políticas liberales para solucionar los nuevos problemas sociales que acarrearon la primera posguerra y el recurso a medidas represivas duras para frenar los movimientos huelguísticos, a excepción de los países donde los partidos gubernamentales fueran representantes o simpatizantes con los intereses de la clase trabajadora.

\section{La creación de los ministerios de trabajo en Europa en la posguerra europea}

El Ministerio de Trabajo suele ser el órgano central responsable de las cuestiones relacionadas con el trabajo, aunque en ocasiones no sea la única autoridad en este campo. La función de Ministerio de Trabajo prototípico es elaborar e implementar las políticas de trabajo a nivel nacional. Históricamente la política laboral de los países occidentales se ha articulado por dos mecanismos: la vía de la regulación y la vía del presupuesto.

Las primeras medidas de la política laboral contemporánea se canalizaron por la regulación del mercado de trabajo, con el objeto de hacer frente a la "cuestión social" o "problema laboral". A partir de las primeras décadas del siglo XX, con el ascenso de los seguros sociales, la vía presupuestaria tomó relieve en las políticas laborales. En torno al año 1913, la intensidad de la política laboral de países occidentales experimentaba diferencias notables. Las políticas laborales en materia de regulación laboral y de seguros sociales mostraban contrastes por países europeos antes de la Primera Guerra Mundial. Mientras que, en el año 1913, el Reino Unido y Alemania habían convergido y destacaban en los logros de regulación laboral a escala europea, en materia de seguros sociales eran los países del Norte de Europa donde estas políticas presupuestarias habían avanzado con mayor celeridad. ${ }^{18}$

Así pues, en el contexto europeo, la política laboral europea durante el período de entreguerras empezaba a tomar nuevos retos. La regulación del mercado de trabajo había sido la estrategia clave de la política laboral desde el siglo XIX pero desde 1918, algunos gobiernos emprendieron o continuaron políticas laborales que exigían de mayor esfuerzo presupuestario, como fue el caso de la financiación pública de los seguros sociales.

\footnotetext{
${ }^{17}$ FEINSTEIN, Charles H.; TEMIN, Peter; TONIOLO, Gianni. The World economy between the world wars, Oxford University Press, 2008.

${ }^{18}$ HUBERMAN, Michael; LEWCHUK, Wayne, op. cit., p. 22-25
} 
Lógicamente, la diversidad de estrategias entre países europeos respondía a proyectos políticos diferenciados y a sus políticas fiscales más o menos redistributivas. ${ }^{19}$

En la medida en que las formas de política laboral se transformaron, las estructuras administrativas públicas laborales por parte de los gobiernos también experimentaron cambios. La administración laboral como campo de gobernanza se remonta a la segunda mitad del siglo XIX cuando se crearon los primeros órganos administrativos. En algunos países, la primera forma de instituciones laborales fueron centros de investigación y estadística, con el propósito de proporcionar a los responsables políticos los datos del mercado de trabajo y de la situación que les permitiera fundamentar la acción legislativa. $^{20}$ En el año 1910, veintidós países europeos (y algunos países latinoamericanos) ya contaban con organismos especializados para supervisar las condiciones laborales. Estas oficinas estadísticas fueron precursoras de los ministerios de trabajo con poderes ejecutivos reales. Con frecuencia, el establecimiento de ministerios de trabajo respondió a la necesidad de los estados para responder ante conflictos o accidentes laborales. De especial relevancia temporal fue la Primera Guerra Mundial, dado que fue un momento prolífico en la creación de nuevos organismos públicos en materia laboral. $^{21}$

El establecimiento de instituciones gubernamentales de rango ministerial dedicadas al Trabajo en los países occidentales obedece a multitud de casuísticas que atienden a la evolución institucional de cada caso. En todo caso, es destacable indicar la coincidencia temporal en muchas de las iniciativas en pro de la fundación de ministerios de trabajo entre los países occidentales (cuadro 1) entorno a la Primera Guerra Mundial e inmediata posguerra. En este sentido, la fundación del Ministerio de Trabajo en España en la primavera de 1920 guarda sintonía y concordancia cronológica con lo acontecido en muchos de los países de su entorno.

\footnotetext{
${ }^{19}$ Para el caso español en perspectiva comparativa, véase PONS, Jerònia y SILVESTRE, Javier (ed), Los orígenes del Estado del Bienestar en España, 1900-1945: los seguros de accidentes, vejez, desempleo y enfermedad, Zaragoza, Prensas Universitarias de Zaragoza 2011. Prensas Universitarias de Zaragoza actualmente se denominan Servicio de Publicaciones de la Universidad de Zaragoza. Sobre las razones del lento avance de los seguros en España antes de la Guerra Civil puede consultarse ESPUELAS, Sergio, La evolución del gasto social en España, 1850-2005, Madrid, Banco de España, 2013, p. 54.

${ }^{20}$ RYCHLY, Ludek, Ministries of Labour: Comparative Overview. Data base, Organigrams, ILO action. Geneva: International Labour Organization. Working Document, 27, 2013, p. 4. "For example, a British statistical office was set up in 1887 and transformed in 1894 into an autonomous section of the Board of Trade with the title "Department of Labour"; the French Office was established in 1891. In Germany, the Commission for Labour Statistics was established even earlier, in 1882, and the Spanish Institute for Social Reform was founded in 1883."

${ }^{21}$ Op. cit., p. 4.
} 
Ciertamente, la forma ministerial de la institución no niega que los asuntos laborales ya fueran tratados por la regulación previa gubernamental, pero se había ejecutado en base a otros organismos de rango inferior, aunque existiera profundas diferencias en la gestión de los asuntos laborales entre países. Con todo, la gestión de temáticas relativas al trabajo a rango ministerial pone en evidencia que los temas laborales habían ganado peso en la agenda de los gobiernos occidentales, que se dotaban de mejores instrumentos para atenderlos. $^{22}$

Cuadro 1.- Creación de los ministerios de trabajo en determinados países occidentales

\begin{tabular}{|l|l|l|}
\hline País & Institución & Año creación \\
\hline Francia & Ministère du Travail & 1906 \\
\hline United Sates & Department of Labor & 1913 \\
\hline United Kingdom & $\begin{array}{l}\text { Ministry of Labour } \\
\text { (New Ministries and Secretaries Act } \\
1916)\end{array}$ & 1916 \\
\hline Norway & Arbeids- og sosialdepartementet & 1916 \\
\hline Netherlands & $\begin{array}{l}\text { Minister van Sociale Zaken en } \\
\text { Werkgelegenheid }\end{array}$ & 1918 \\
\hline Germany & Reichsarbeitsministeri & 1919 \\
\hline España & Ministerio de Trabajo & 1920 \\
\hline Italie & $\begin{array}{l}\text { Ministero del lavoro e della previdenza } \\
\text { Sociale }\end{array}$ & 1920 \\
\hline
\end{tabular}

En el articulado de creación de la OIT del año 1919 ya se concretó la manera en que cada administración de los países miembros se relacionaría con el organismo internacional. Por ejemplo, el nuevo diseño institucional implicaba una comunicación directa y coordinada de cada administración gubernamental involucrada con la OIT (artículo 397) y, sobre todo, una mayor exigencia de cada país miembro con los compromisos subscritos con la OIT, para lo cual la organización internacional exigía un informe anual sobre la efectividad de los compromisos, aportando los datos que el Consejo estimara pertinentes (artículo 408). Sin olvidar que, a partir de 1919, la intensa actividad realizada por la OIT durante el período de entreguerras comportó la publicación de múltiples informes temáticos, los cuales se nutrían de documentaciones y estadísticas de los países participantes en esta organización.

\footnotetext{
${ }^{22}$ No podemos olvidar que, a nivel teórico, las funciones, el marco de actuación de políticas públicas y de gestión presupuestarias de una estructura ministerial eran superiores al de un organismo autónomo. Otra cuestión distinta es dilucidar si esta potencialidad de actuación administrativa de políticas públicas en materia laboral se ejerció o no.
} 
Este nuevo marco de cooperación internacional con la OIT exigió que los gobiernos nacionales dispusieran de departamentos gubernamentales especializados, ya que la OIT buscaba interlocutores directos que garantizasen el cumplimento de los compromisos subscritos en materia laboral. El nuevo funcionamiento articulado en la fundación de la OIT suponía un cambio de las relaciones internacionales en materia laboral y nuevos interlocutores gubernamentales, dado que previamente esta tarea había ido a cargo de los diplomáticos tradicionales.

\section{El entorno particular del caso español}

Pese a la neutralidad española, la Gran Guerra alteró la economía y la sociedad españolas, socavando el sistema político de la Restauración en una grave y profunda crisis, con derivadas políticas, económicas y sociales.

La Primera Guerra Mundial tuvo una incidencia sectorial diversa también en España. La alteración de la demanda externa e interna derivada del conflicto internacional afectó favorablemente a determinados sectores agrarios (los más tradicionales), industriales (energético, textil y químico) y de los servicios (empresas comerciales, compañías navieras y servicios financieros). Las consecuencias económicas de la coyuntura bélica fueron dispares por sectores económicas. Mientras que la elevada inflación generó un deterioro de los salarios reales de los trabajadores asalariados españoles, ${ }^{23}$ los empresarios de los sectores económicos favorecidos por la contienda registraron beneficios espectaculares. ${ }^{24}$

La primera guerra mundial amplió la desigualdad social en España. Entre 1914 y 1917 los grandes beneficiarios del ciclo bélico fueron los empresarios y capitalistas. Sólo desde el año 1918 se registraron importantes alzas salariales para los trabajadores. "Pero el aumento salarial no implicó una redistribución de la renta que restaurara la situación previa a la guerra: la desigualdad de los ingresos se mantuvo durante la década de 1920

\footnotetext{
${ }^{23}$ Sobre la evolución de los precios al consumo en España, diversas estimaciones muestran que durante los años de la Primera Guerra Mundial rompieron la estabilidad de los precios en España desde 1873 hasta el conflicto. Pese a la neutralidad española, los precios de bienes de consumo casi se duplicaron durante estos años, pasando de nivel 100 en el año 1913 a 190 en el año 1920. MALUQUER DE MOTES, Jordi, La inflación en España. Un Índice de precios de consumo 1830-2012, Estudios de Historia Económica n ${ }^{\circ} 64$, Madrid, Banco de España, 2013, p. 104, cuadro A1.6.

${ }^{24}$ Sobre el aumento de la demanda de algunos sectores empresariales beneficiados por la coyuntura de la Primera Guerra Mundial (como el sector hullero, químico, textil y siderometalúrgico, así como el negocio marítimo y bancario) así como el uso de los extraordinarios beneficios empresariales alcanzados, véase un primer análisis del tema en NADAL, Jordi; FONTANA, Josep, "España, 1914-1970” en CIPOLLA, Carlo M. (Coord.), Historia económica de Europa, vol. 6, tomo 2, 1980, p. 95-105.
} 
en niveles elevados, por encima de los prebélicos. ${ }^{25}$ La desigualdad económica amplió la fractura social, mientras la rigidez del sistema fiscal español era incapaz de adaptarse a la nueva situación, ya que apenas se gravaron los beneficios empresariales. ${ }^{26}$

Un episodio representativo de las tensiones latentes se puso de manifiesto en la crisis del sistema de la Restauración del año 1917, cuando eclosionaron la crisis militar, territorial y social, lo que supuso una "crisis política e institucional generalizada" ${ }^{27} \mathrm{El}$ descontento de los cuadros del ejército conllevó la caída del gobierno de García Prieto substituido por Eduardo Dato en junio de 1917. En julio del mismo año, la asamblea de parlamentarios exigió la convocatoria de Cortes constituyentes y cambios en la organización del estado hacia una estructura menos centralizada, pero la respuesta llegó con su disolución por la fuerza pública. Finamente, la huelga general de agosto de 1917 convocada por la UGT (con el apoyo de la CNT) consiguió inicialmente paralizar las grandes zonas industriales, urbanas y mineras durante una semana. Una vez más, la represión militar a las órdenes del gobierno fue la única respuesta gubernamental a las peticiones sindicales.

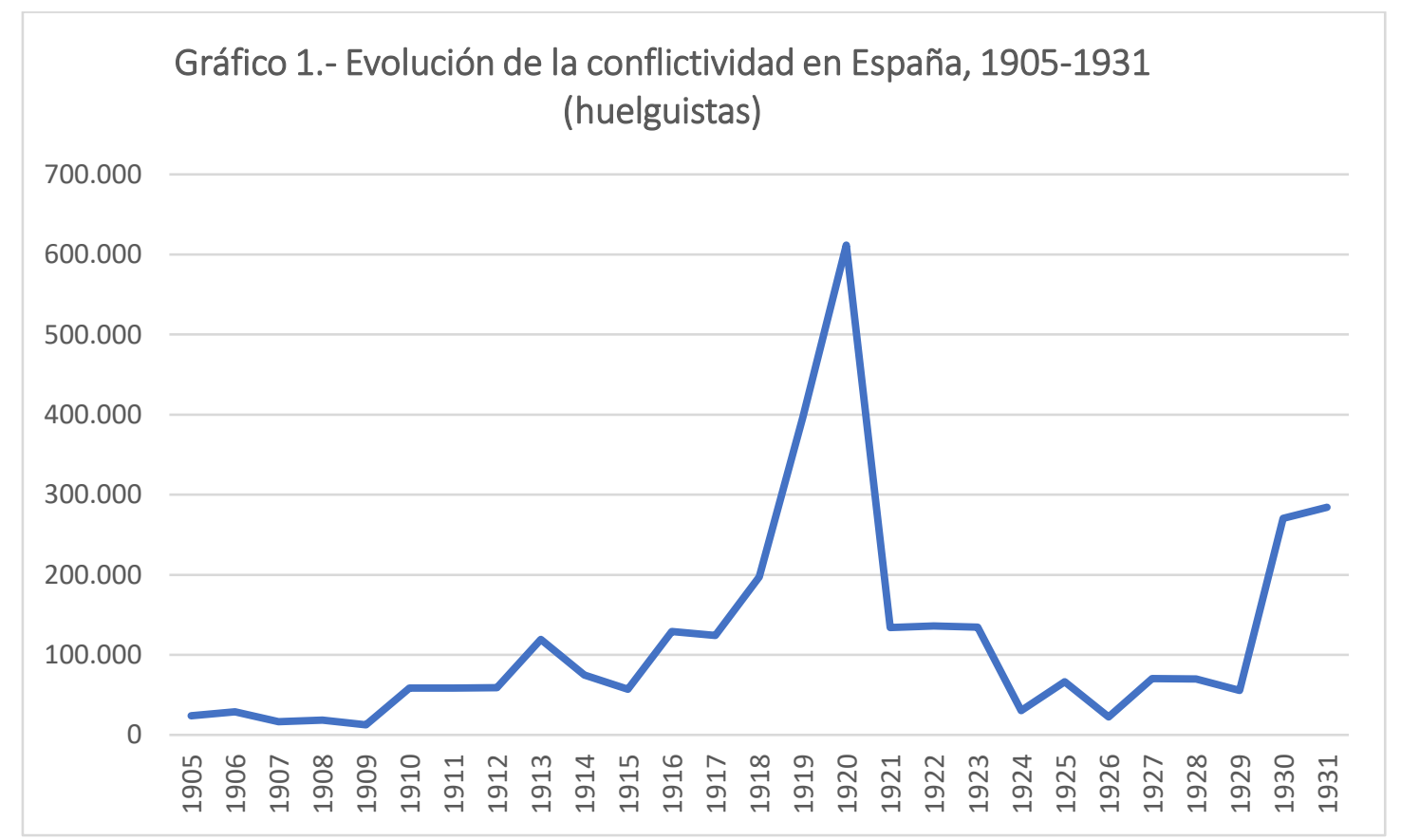

Fuente: SOTO CARMONA, Álvaro, "El ciclo largo de la conflictividad social en España (1868-1986)", Revista de Trabajo y Seguridad Social, 2, (abril-junio 1991), 157-179.

\footnotetext{
${ }^{25}$ CARRERAS, Albert y TAFUNELL, Xavier. Entre el imperio y la globalización. Historia económica de la España Contemporánea. Barcelona: Crítica, 2018, p. 188-192; la cita corresponde a la p. 192.

${ }^{26}$ MARTORELL LINARES, Miguel, "No fue aquello solamente una guerra, fue una revolución: España y la Primera Guerra Mundial”, Historia y Política, 26, 2011, p. 25.

${ }^{27}$ PALACIO, Juan Ignacio, "Crisis política y crisis institucional: la experiència del Instituto de Reformas Sociales en el período 1914-1924” en GARCÍA DELGADO, José Luís (ed) La crisis de la Restauración: España, entre la Primera Guerra Mundial y la Segunda República, Madrid, Siglo XXI, 1986, p. 276.
} 
A la huelga de 1917 le siguieron tres años de conflictividad excepcional durante el primer tercio del siglo XX en España, tal y como muestra el gráfico 1. La peculiaridad de estos años conllevó graves enfrentamientos y una fuerte polarización social entre las organizaciones obreras de clase y las organizaciones patronales, ambas vez más radicalizadas y violentas.

A título de ejemplo, es interesante relatar el episodio político y socioeconómico que conllevó la jornada de ocho horas en España. Nos referimos al Real Decreto del 3 de abril de 1919, por el que se fijaba en ocho las horas al día y cuarenta y ocho semanales de la jornada legal de todos los trabajos. La nueva jornada máxima legal había sido precedida por la huelga de La Canadiense (empresa de producción eléctrica denominada Barcelona Traction, Light and Power) del 18 febrero al 20 marzo de 1919, a manos de la Confederación Nacional del Trabajo (CNT), sindicato de clase anarcosindicalista. Durante muchos días, la huelga había paralizado fábricas y tranvías, y había dejado sin luz a multitud de establecimientos y hogares. Después de la declaración de estado de alarma por Milans del Bosch, la intervención del gobernador civil Carles Montañés y demás autoridades comportó la aceptación de la jornada de 8 horas firmada por el presidente del gobierno liberal de Romanones, temeroso de los ecos de la revolución rusa. ${ }^{28}$ España encabezaba en Europa la aceptación de la jornada de trabajo de 8 horas en $1919 .{ }^{29}$

La nueva jornada de ocho horas de abril de 1919 estaba originalmente prevista su instauración en el primero de octubre del mismo año, una vez los comités paritarios constituidos antes del mes de julio hubieran propuesto las industrias o especialidades objeto de excepción por imposibilidad de aplicación de la nueva normativa sobre la jornada laboral. La Real Orden del 15 de enero de 1920 especificaría de forma extensa y pormenorizada las excepciones a la jornada máxima legal, que afectaba en especial a los trabajadores del sector agrario y del servicio doméstico. Las disposiciones adicionales que regularon la implantación de la jornada de ocho horas también preveían que el recorte de la jornada no comportaría consecuencias negativas en las retribuciones obreras. ${ }^{30}$ Las consecuencias fueron evidentes: las retribuciones salariales de los trabajadores

\footnotetext{
${ }^{28}$ BENGOECHEA, Soledad y SANTOS, Maria Cruz. "La vaga de la Canadenca i el locaut empresarial", Arraona, 37, 2017-18, p. 108.

${ }^{29}$ Gaceta de Madrid no 94, de 4 de abril de 1919, Real Decreto de 3 de abril de 1919: Jornada máxima legal en todos los Trabajos, en VVAA, La legislación social en la Historia de España. De la Revolución liberal a 1936, Madrid, Congreso de los Diputados, 1987, p. 109

${ }^{30}$ Gaceta de Madrid no 16 , de 16 de enero de 1920 "La reducción de la jornada no podrá ser causa determinante de una disminución correlativa de los salarios y remuneraciones. Exceptúase únicamente el caso de que éstos hayan tenido aumento en los dos años últimos y conste de un modo fehaciente que el aumento se hizo como compensación al mayor número de horas de trabajo". Artículo 2 de la Real Orden del 15 de enero de 1920: Normas para la aplicación de la Jornada máxima, VVAA, op. cit, p. 126.
} 
industriales, que se habían reducido en términos reales hasta 1917, empezaron a recuperarse en los dos años siguientes. El incremento de costes laborales para los empresarios industriales fue muy notable en un breve lapso temporal, lo que dificultaría, en el caso de la industria textil, la competitividad exterior ${ }^{31}$.

Los empresarios españoles consideraron la regulación de la jornada de ocho horas como "dictadura de ley" y su oposición fue frontal. El locaut empresarial de las principales ciudades industriales se decretó en el Segundo Congreso Patronal Español y entró en vigor el 3 de noviembre de 1919. De esta manera, la Federación Patronal se enfrentaba a su enemigo principal, la Confederación Nacional del Trabajo, lo que a su vez había de significar un auténtico pulso al gobierno liberal.

La duración del locaut se prolongó durante cuatro meses (desde noviembre de 1919 a enero de 1920) y supuso la paralización industrial durante ochenta y cuatro días en Barcelona. El largo cese de las fábricas condenó a la hambruna a multitud de familias obreras, una vez fueron vaciándose las cajas de solidaridad obrera. En definitiva, buena parte de los objetivos fueron conseguidos: se produjo un cambio de gobierno, se suprimió el sindicalismo y se endureció la posición de la patronal con los obreros, ya que las relaciones contractuales volvieron a realizarse de manera individualizada. Las posiciones de la patronal y la CNT acabaron radicalizándose aún más: el pistolerismo y los ataques anarquistas se reafirmaron en la escena política y social hasta $1923 .{ }^{32}$

Cuatro meses después de la finalización del locaut empresarial más largo de la historia del siglo XX en España, que tuvo un impacto económico y social inusitado en términos de jornadas no trabajadas, se creaba el Ministerio de Trabajo en España.

\section{Oportunidad en la creación del Ministerio de Trabajo en España}

La constitución de la nueva administración ministerial podría suponer la ratificación política de que las organizaciones públicas existentes habían quedado obsoletas para hacer frente a los nuevos desafíos en materia laboral. Hasta el Real Decreto del 8 de mayo de 1920, ${ }^{33}$ el Instituto de Reformas Sociales (1903-1924), heredero de la Comisión de Reformas Sociales (1883), se había dedicado de las cuestiones sociales y de previsión popular, ocupándose de los trabajos de información, de preparación legislativa y de

\footnotetext{
${ }^{31}$ LLONCH, Montserrat. "Jornada, salarios y costes laborales en el sector textil catalán, (1891-1936)", Revista de Historia Industrial, 26 2004, p.101-140.

${ }^{32}$ BENGOECHEA, Soledad, El locaut de Barcelona (1919-1920), Barcelona, Curial,1998.

${ }^{33}$ Gaceta de Madrid no 130, 9 de mayo de 1920, p. 538.
} 
inspección del trabajo. ${ }^{34}$ Fruto de la labor de estas instituciones, la aparición de la regulación laboral estaba ya avanzada en el momento de constitución del nuevo Ministerio de Trabajo. Después de la muerte del presidente Azcárate en 1917, el IRS, constituido como un organismo autónomo a cargo del Ministerio de Gobernación, estaba en proceso de reforma. Pero después de la crisis de 1917, se pusieron de relieve los límites de la capacidad ejecutiva del Instituto de Reformas Sociales. ${ }^{35}$

En mayo de 1920, la situación política española seguía inmersa en la profunda crisis del sistema político de la Restauración. Desde el mes de junio de 1917 hasta mayo de 1920, en tres años, se sucedieron en España ocho gobiernos, con una duración media de tres meses. ${ }^{36}$ En estos años, la permanencia máxima del ejecutivo había ido a cargo del gobierno de concentración liderado por el conservador Antonio Maura, que desarrolló su tarea a lo largo de siete meses. Finalmente, después de las terceras elecciones en tres años, el día 5 de mayo se abrió paso el gobierno de Eduardo Dato, que gobernó durante diez meses. El gobierno Dato abrió la convocatoria de las Cortes con un extenso debate sobre la situación en Cataluña, donde se aplicaba la "ley de fugas" a los sindicalistas detenidos. ${ }^{37}$ Mal presagio, su gobierno finalizó dramáticamente con su defunción, tras un atentado anarquista del 8 de marzo de 1921 en Madrid.

\footnotetext{
${ }^{34}$ Gaceta de Madrid no 63, de 4 de marzo de 1906, Reglamento para el Servicio de la Inspección del Trabajo, creado por el Real Decreto de 1 de marzo de 1906.

${ }^{35}$ Sobre el papel del Instituto de Reformas Sociales y del Ministerio de Trabajo es útil la revisión de SOTO CARMONA, Álvaro El Trabajo industrial en la España contemporània (1874-1936), Barcelona, Anthropos, 1989, p. 263-286, PALACIO, Juan Ignacio. La institucionalización de la reforma social en España (18831924), Madrid, Ministerio de Trabajo y Seguridad Social, 1988, p. 107-125, así como un estudio más recinte que presenta un buen estado de la cuestión en MARRAUD GONZÁLEZ, Gerardo, "En los orígenes de la Administración sociolaboral: del Instituto de Reformas Sociales al Ministerio de Trabajo", Revista del Ministerio de Trabajo y Asuntos Sociales, 2003, p. 155 y ss.

${ }^{36}$ (1) El gobierno de Eduardo Dato Iradier (del 11 de junio de 1917 al 3 de noviembre de 1917) duró poco más de cuatro meses, (2) el gobierno de concentración nacional de Manuel García Prieto también (del 3 noviembre de 1917 al 22 de marzo de 1918). El tercer gobierno que le sucedió fue (3) el gobierno nacional de Antonio Maura de siete meses de duración (hasta el 9 noviembre de 1918), continuado por (4) el gobierno liberal de Manuel García Prieto que no alcanzó el mes de actividad. A continuación, se abrió paso al convulso (5) gobierno del liberal del Conde de Romanones (del 5 de diciembre de 1918 hasta el 15 de abril de 1919), de cuatro meses de vigencia con la suspensión de garantías constitucionales en enero de 1919. Tras la convocatoria electoral (6) el gobierno conservador de Antonio Maura estuvo en vigor durante tres meses (del 15 de abril al 20 de julio de 1919). Le tomó el relevo un (7) nuevo gobierno conservador, esta vez bajo la presidencia de Joaquín Sánchez de Toca que gobernó durante 4 meses escasos, al que le sucedió un (8) otro gobierno de concentración nacional de Manuel Allendesalazar Muñoz de la misma duración que el anterior.

${ }^{37}$ Sobre la situación política en que se encuentra España durante el gobierno Dato véase MORENO LUZÓN, Javier, "Partidos y Parlamento en la Crisis de la Restauración", en Mercedes CABRERA (dir) Con luz y taquígrafos. El Parlamento en la Restauración (1913-1923). Madrid: Taurus, 1998, p. 65-102.
} 
La situación económica tampoco era favorable, ya que España atravesaba una crisis posbélica (1919-1922), provocada por el reajuste de la demanda al finalizar la guerra mundial. La caída de las exportaciones y el incremento espectacular de las compras exteriores aplazadas durante los años de guerra europea tuvieron un impacto en la actividad productiva, afectando a la bajada de los precios y de la producción. El correctivo depresivo supuso la desaparición de las empresas marginales, las quiebras de bancos, deflación y paro. Los protagonistas de la recesión fueron los sectores industriales de la minería del carbón, la industria textil y la siderurgia, los mismos que habían sido beneficiados durante la guerra. La cuestión central que nos ocupa es que la crisis económica posbélica, y su paro asociado, instigaron aún más el clima de radicalidad política y social de los años 1918-1920, en medio de la gran pandemia de gripe. ${ }^{38}$

En este contexto, la iniciativa del gobierno conservador de Eduardo Dato de crear el Ministerio de Trabajo el 8 de mayo de 1920, tres días después de su constitución, podría interpretarse como una propuesta gubernamental para reconducir la crispada situación política y social existente en España. ${ }^{39}$ La propuesta no se improvisó, no era nueva y ya se encontraba en fase de estudio, ${ }^{40}$ pero el momento de creación de la nueva organización administrativa ministerial se ajustaba a la urgencia de los tiempos de la situación española y al contexto internacional. En mayo de 1920 la delicada situación política española urgía dar alguna respuesta gubernamental.

El gobierno de Dato argumentaba también que la propuesta ministerial obedecía a factores administrativos, en el sentido de sumar todos los centros y organismos dependientes del Estado y asociados a diferentes ministerios dedicados al mundo del trabajo en un único ministerio. En el artículo primero del Real Decreto de su creación se establecía que: "En virtud de la autorización concedida al Gobierno en la disposición octava complementaria de la ley del Presupuestos vigente, se crea el ministerio de Trabajo, al que quedan asignados, desde luego, los Institutos de Reformas Sociales y de Nacional de Previsión, la sección de Reformas Sociales del ministerio de la Gobernación, el Negociado de Trabajo de la Dirección general de Comercio, Industria y Trabajo el

\footnotetext{
${ }^{38}$ La pandemia de gripe de 1918-19 se articuló en torno a tres olas bien definidas, con mortalidad desigual por edad, con especial virulencia entre los jóvenes adultos, y con incidencia territorial diferenciada según se desprende de los estudios del caso español. ECHEVERRI DÁVILA, Beatriz, "En el centenario de la gripe española. Un estado de la cuestión” Revista de Demografía Histórica, 36, 1, 2018, p. 17-42.

${ }^{39}$ Eduardo Dato había tenido un papel relevante en materia de regulación laboral, al ser el artífice de la ley de accidentes de trabajo y las condiciones laborales de mujeres y niños. ESPUNY, Maria Jesús, "Eduardo Dato y la legislación obrera", Historia social, 43, 2002, p. 3-14.

${ }^{40}$ Sobre el proceso de gestación del Ministerio de Trabajo que arranca en el año 1908, véase MARRAUD GONZÁLEZ, Gerardo, "En los orígenes de la Administración sociolaboral: del Instituto de Reformas Sociales al Ministerio de Trabajo”, Revista del Ministerio de Trabajo y Asuntos Sociales, 2003, p. 155 y ss.
} 
Consejo de Emigración y el Patronato de ingenieros y obreros pensionados en el extranjero". ${ }^{41}$

Esta reorganización institucional pretendía desarrollar sus cometidos con mayor actividad y eficacia que escondía una tendencia absorbente de la Administración Central. ${ }^{42}$ Además, la nueva administración contaba con consignaciones fijas en los presupuestos, y suponía que el margen de actuación de la nueva autoridad laboral en España podía ampliarse por la vía presupuestaria, además de tener potestad reguladora propia. La acogida de diversos rotativos de la prensa nacional fue escéptica, porque dudaban de su eficacia para resolver los desafíos abiertos en materia laboral. ${ }^{43}$

Los propósitos iniciales que defendían desde el ministerio no eran tampoco muy ambiciosos. De hecho, el primer responsable del Ministerio de Trabajo durante los primeros diez meses de vida de la institución, Carlos Cañal Migolla explicaba en sus primeras manifestaciones la vocación de que la nueva institución avanzara hacia la armonía entre las clases obreras y del resto de elementos de producción, o sea, el interés por encauzar y canalizar el descontento social desde una óptica moral. Definía al nuevo ministerio como nexo de organismos autónomos ya existentes en la creación como de nuevos, pese a declarar que no preveía crear ningún organismo adicional ni tampoco contractar nuevos empleados. Según el ministro: "En cuanto a la función del nuevo organismo, deseo que se hagan estadísticas, lo más completas posibles, que ya se sabe

\footnotetext{
${ }^{41}$ Gaceta de Madrid no 130, 9 de mayo de 1920. Real Decreto del 8 de mayo de 1920 "Real Decreto"

${ }^{42}$ PALACIO, op. cit, p. 107.

${ }^{43}$ A título de ejemplo de las impresiones periodísticas durante los primeros días que siguieron a la creación del Ministerio de Trabajo:

"Todo ciudadano encontrará muy atinado la creación del ministerio de Trabajo. Los dos elementos que colaboran en la producción, así como la economía nacional, que sufre las consecuencias de las desavenencias y litigios entre ambos, sentían la necesidad de un organismo que restableciera el equilibrio y cuidase de su futura estabilidad. El Gobierno del Sr. Dato nos ha dado el instrumento; falta ahora saber si su actuación será eficaz (...) La creación del ministerio del Trabajo ¿servirá a transformar esas organizaciones consultivas en instrumentos con actuación directa e independiente? ¿Evolucionarán de organismos académicos que son, en intermediarios o jueces activos? Y todavía: ¿su actuación será fuera de la órbita de doctrinas políticas para moverse en el campo más amplio de la economía? Sin tener las respuestas afirmativas a esas preguntas previas, no se puede creer en la eficacia del nuevo ministerio"
} (AZPEITUA, Antonio. "El Ministerio de Trabajo", ABC, 14 de mayo de 1920, p. 6)

"El nuevo departamento si no está creado con vistas a la galería y responde a la importancia de su nombre, puede llenar los fines prácticos que cumple en otros países".

(CASTELL, Ángel Ma, “Apuntes de la semana”, Blanco y Negro, Madrid, 16 de mayo de 1920, p. 12) "Acaba de crearse el ministerio de Trabajo entre la general indiferencia. (...) Se ha seguido, pues, el eterno procedimiento de nuestra política caduca... que no acaba de caducar nunca. Crear los órganos antes de los servicios, multiplicar el mandarinato antes que fomentar los servicios públicos".

(ANDRENIO, "Ministerio de servicios públicos", La Vanguardia, Barcelona, 19 de mayo de 1920, p. 8.). 
cuánta importancia tienen para el trabajo y la producción; y me propongo hacer cumplir las actuales leyes sociales antes de pensar en nuevas disposiciones." 44

De las palabras del ministro Cañal destaca su propósito de mejora en la elaboración de información estadística laboral en España como mecanismo para articular políticas laborales en España. Sin un conocimiento exhaustivo de la realidad laboral, la posibilidad de emprender políticas laborales era inviable. El tema no era menor, dado el panorama de la estadística laboral en España en 1920. ${ }^{45}$ En segundo lugar, el ministro Cañal mostraba su propósito de hacer cumplir la obra legislativa laboral, más que extenderse en nuevas propuestas de regulación. La máxima autoridad laboral cuestionaba así de manera explícita el grado de cumplimento de la regulación laboral en España.

La prensa española del momento también puso énfasis en que la constitución del nuevo ministerio respondía a razones de agenda internacional, presente en los Tratados de paz y las conferencias internacionales que habían seguido al final de la guerra. La política laboral estaba sobre la mesa de los ejecutivos europeos y España no se quedó atrás en la creación de una institución específica. A su vez, la coordinación de los países miembros de la OIT requería de nuevas gestiones y funciones de los gobiernos en materia laboral. Debe recordarse que tres meses después de la creación del Ministerio de Trabajo se estableció un negociado referido a disposiciones de carácter internacional en relación con la OIT, por lo que la coordinación del nuevo ministerio con la OIT fue uno de los primeros ámbitos de actuación del Ministerio de Trabajo.

\footnotetext{
${ }^{44}$ Así se recoge en la entrevista que le realizaron al ministro Carlos Cañal y se publicó en la prensa. "La labor del Gobierno. La Organización del Ministerio de Trabajo”, ABC, 12 de mayo de 1920, p .7.

45 Aunque el Servicio de Estadística del Trabajo, dependiente del Ministerio de Gobernación, se creó a partir del Decreto de 8 de agosto de 1894, no abundaba la estadística seriada sobre el mercado de trabajo en España durante el primer tercio del siglo XX, a excepción de las Memorias Generales de la Inspección del Trabajo publicadas por el Instituto de Reformas Sociales entre los años 1907 y 1923 . Lamentablemente, para temas clave del mundo del trabajo, como son los salarios, la información estadística publicada por los organismos oficiales es fragmentaria y de baja calidad para el periodo previo a la Guerra Civil, pese a los loables esfuerzos pioneros realizados por el Ministerio de Trabajo para avanzar en la cobertura de la información estadística en base. Uno de sus logros fue la elaboración de MINISTERIO DE TRABAJO, DIRECCIÓN GENERAL DEL TRABAJO, Estadísticas de salarios y jornadas de trabajo referidas al periodo 1914-1925, Madrid, 1927 y MINISTERIO DE TRABAJO, DIRECCIÓN GENERAL DEL TRABAJO, Estadísticas de salarios y jornadas de trabajo referidas al periodo 1914-1930, Madrid, 1931. En el exiguo panorama de la estadística laboral en la España contemporánea. la mencionada estadística pese a sus evidentes limitaciones- se presenta como pionera elaboración estadística con metodología moderna, realizada mediante una encuesta anual enviada a las empresas por localidades, según se recoge en los archivos municipales.
} 
En definitiva, la creación del Ministerio de Trabajo en 1920 obedeció a la oportunidad de la nueva administración desde la perspectiva internacional, acorde con la situación política y social española y con el reajuste propio de la administración laboral en España. Otra cuestión muy distinta, no menor pero lejos del alcance de estas páginas, es evaluar la obra realizada por parte del nuevo Ministerio de Trabajo en el ámbito de la regulación laboral y de la protección social.

\section{Conclusiones}

El Ministerio de Trabajo español creado en mayo de 1920 fue una institución coetánea a buena parte de los países europeos. A su vez, fue una institución oportuna en el panorama internacional que siguió a la Primera Guerra Mundial, cuando la conflictividad social acrecentó las necesidades de los gobiernos europeos para encontrar salidas mediante políticas sociales (regulación laboral e incremento de los seguros sociales).

La creación de la OIT por parte de la Sociedad de Naciones en 1919 representó un nuevo impulso a favor de la coordinación internacional de los estados miembros, que requería de requisitos superiores de gestión, información y compromiso. El destacado papel del nuevo organismo internacional actuó como aglutinador en la articulación administrativa a nivel laboral y abrió paso a nuevos retos y procedimientos para encarar la problemática laboral a nivel nacional e internacional.

La crisis política del régimen político de la Restauración, la crisis económica posbélica y el clima de radicalidad social y violencia hacían preciso de cualquier institución que pudiera reconducir la situación sin recurrir al tradicional recurso de la represión militar. Por ello, la creación del Ministerio de Trabajo en 1920 fue providencial. Pero la oportunidad de cualquier institución explica su creación, pero no su desarrollo y obra, lo que requerirá de nuevas aportaciones. El alcance de la obra del nuevo Ministerio de Trabajo es un tema controvertido, aún objeto de discusión, que debería contemplar para su balance un marco comparativo sobre los objetivos propuestos, su actuación reguladora y presupuestaria, así como el tiempo de ejecución de las políticas laborales propuestas. ${ }^{46}$

\footnotetext{
${ }^{46}$ La visión tradicional personificada Mariano González Rothvoss (funcionario vinculado a los cuerpos técnicos del Ministerio de Trabajo) estipula que el Ministerio de Trabajo creado en 1920 no tuvo ambición y su única misión fue la de conferir jerarquía administrativa a las propuestas del Instituto de Reformas Sociales, y con el tiempo asumiría una acción "organofágica" eliminando otros organismo existentes en materia laboral como recoge DE LA VILLA, Luís Enrique, "Los orígenes de la administración laboral en España", Documentación Administrativa, 131, 1969, p. 25. En una interpretación opuesta que analiza con mayor detalle los ámbitos de actuación del Ministerio de Trabajo entre 1920 y 1923, encontramos la contribución de Daniel Vallès que pone en valor la tarea realizada en los primeros años de existencia, véaseVALLÉS, Daniel, “El Ministerio de Trabajo 1920-1923: iniciativas relevantes: Corporativismo, casas
} 


\section{Bibliografía}

ALDCROFT, Derek H., Historia de la economia europea, 1914-1980. Barcelona, Crítica, 1989.

BAENA DEL ALCÁZAR, Mariano, Curso de Ciencia de la Administración, Madrid, Tecnos, 1996.

BENGOECHEA, Soledad, El locaut de Barcelona (1919-1920), Barcelona, Curial, 1998.

BENGOECHEA, Soledad; SANTOS, Maria Cruz, "La vaga de la Canadenca i el locaut empresarial, Arraona, no 37, 2017-2018, p. 106-115.

CABRERA, Mercedes; JULIÁ, Santos; MARTÍN ACEÑA, Pablo (Comp.), Europa en crisis: 1919-1939, Madrid, Pablo Iglesias, 1991.

CARRERAS, Albert; TAFUNELL, Xavier, Entre el imperio y la globalización. Historia económica de la España Contemporánea, Barcelona, Crítica, 2018.

CUESTA BUSTILLO, Josefina, Las relaciones entre España y la Organización Internacional del Trabajo (1919-1939), Madrid, Consejo Económico y Social, 1994.

DAVIS, Mary Davis, “An historical introduction to the campaign for equal Pay". TUC \& London Metropolitan University, (URL=website.ttp://www.unionhistory.info/ equalpay/roaddisplay.php?irn=820 (acceso 11 marzo 2021).

DE LA VILLA, Luís Enrique, "Los orígenes de la administración laboral en España", Documentación Administrativa, $\mathrm{n}^{\mathrm{o}}$ 131, 1969, p. 11-49.

DOUGLAS, Mary, Cómo piensan las instituciones, Madrid, Alianza Universidad, 1996.

ECHEVERRI DÁVILA, Beatriz, "En el centenario de la gripe española. Un estado de la cuestión" Revista de Demografía Histórica, no 36, vol. 1, 2018, p. 17-42.

ENGERMAN, Stanley L., "The History and Policial Economy of International Labor Standards" in BASO, Kaushik; HORN, Henrik; ROMÁN, Lisa; SHAPIRO, Judith (Ed.) International Labor Standards. Blackwell Publishing, 2003, p. 7-83.

baratas e inspección de trabajo", Iuslabor, 2, 2020, 131-159. Otros aspectos de esta discusión pueden verse recopilados en Gerardo MARRAUD, op. cit. 
ESPUELAS BARROSO, Sergio, La evolución del gasto social en España, 1850-2005, Madrid, Banco de España, 2013.

ESPUNY, M. Jesús, “Eduardo Dato y la legislación obrera”, Historia social, n 43, 2002, p. 3-14.

FEINSTEIN, Charles H.; TEMIN, Peter; TONIOLO, Gianni, The World economy between the world wars, Oxford University Press, 2008.

FELIU, Gaspar y SUDRIÀ, Carles (2006) Introducció a la història econòmica mundial. València: Universitat de Barcelona y Universitat de Valencia.

HUBERMAN, Michael; Lewchuk, Wayne, "European economic integration and the labour compact, 1850-1913”, European Review of Economic History, n 7, 2003, p. 3-41.

International Labour Office (1920) The Labour Provisions of the Peace Treaties. Geneva

KEYNES, John Maynard, Las consecuencias económicas de la paz, Barcelona, Crítica, 1987.

LLONCH CASANOVAS, Montserrat, Jornada, salarios y costes laborales en el sector textil catalán, (1891-1936) Revista de Historia Industrial, nº 26, 2004, p. 101-140.

MALUQUER DE Motes, Jordi, "El quart cavaller de l'Apocalipsi: Impacte demogràfic de la grip de 1918-1920 a l'Europa Llatina i als països de parla catalana", Butlletí de la Societat Catalana d'Estudis Històrics, n 31, 2020, p. 393-341.

MALUQUER DE MOTES, Jordi, La inflación en España. Un Índice de precios de consumo 1830-2012. Estudios de Historia Económica nº 64, Madrid, Banco de España, 2013.

MARRAUD GONZÁLEZ, Gerardo, "En los orígenes de la Administración sociolaboral: del Instituto de Reformas Sociales al Ministerio de Trabajo", Revista del Ministerio de Trabajo y Asuntos Sociales, 2003, p. 141-166.

MARTORELL LINARES, Miguel, "No fue aquello solamente una guerra, fue una revolución: España y la Primera Guerra Mundial”, Historia y Política, nº 26, 2011, p. 1745 . 
MINISTERIO DE TRABAJO, DIRECCIÓN GENERAL DEL TRABAJO, Estadísticas de salarios y jornadas de trabajo referidas al periodo 1914-1925, Madrid, 1927.

MINISTERIO DE TRABAJO, DIRECCIÓN GENERAL DEL TRABAJO, Estadísticas de salarios y jornadas de trabajo referidas al periodo 1914-1930, Madrid, 1931.

MORENO LUZÓN, Javier, "Partidos y Parlamento en la Crisis de la Restauración”, en Mercedes CABRERA (dir) Con luz y taquígrafos. El Parlamento en la Restauración (1913-1923), Madrid, Taurus, 1998, p. 65-102.

MÜLLER-JENTSCH, Walther, Industrial democracy: Historical development and current challenges, Management Revue, n 19, vol. 4, 2008, p. 260-273.

NADAL, Jordi; FONTANA LÁZARO, Josep, “España, 1914-1970” en CIPOLLA, Carlo M. (Coord), Historia económica de Europa, vol. 6, Tomo 2, Barcelona, Crítica, 1980, p. 95-163.

O'ROURKE, Kevin H; WILLIAMSON, Jeffrey G., Globalization and History. The evolution of a Nineteenth-Century Atlantic Economy, Cambridge \& London, The MIT Press, 1999.

PALACIO, Juan Ignacio, "Crisis política y crisis institucional: la experiència del Instituto de Reformas Sociales en el período 1914-1924” en GARCÍA DELGADO, José Luís (ed) La crisis de la Restauración: España, entre la Primera Guerra Mundial y la Segunda República, Madrid, Siglo XXI, 1986, p. 271-289.

PALACIO, Juan Ignacio. La institucionalización de l a reforma social en España (18831924), Madrid, Ministerio de Trabajo y Seguridad Social, 1988, p. 107-125.

PONS PONS, Jerònia y SILVESTRE RODRÍGUEZ, Javier (Eds.), Los orígenes del Estado del Bienestar en España, 1900-1945: los seguros de accidentes, vejez, desempleo y enfermedad, Prensas Universitarias de Zaragoza, 2011.

RODRIK, Dani, The Globalization Paradox-Democracy and the Future of the World Economy, New York, W.W. Norton \& Company, 2011.

RYCHLY, Ludek, Ministries of Labour: Comparative Overview. Data base, Organigrams, ILO action. Geneva: International Labour Organization. Working Document, $\mathrm{n}^{\mathbf{0}} 27,2013$. 
SOTO CARMONA, Álvaro El Trabajo industrial en la España contemporània (18741936), Barcelona Anthropos, 1989.

SOTO CARMONA, Álvaro, El ciclo largo de la conflictividad social en España (18681986), Revista de Trabajo y Seguridad Social, no 2, 1991, p. 157-179.

TAYLOR, Andrew J., Trade Unions and Politics. A comparative introduction, London, Macmillan, 1989.

VALLÈS MUÑÍO, Daniel, "El Ministerio de Trabajo 1920-1923: iniciativas relevantes: Corporativismo, casas baratas e inspección de trabajo", Iuslabor, no 2, 2020, p. 131-159.

VERGARA, Jorge Iván, Teorías conservadoras y teorías críticas con las instituciones sociales, Revista de Ciencias Sociales, n 11, 2001, p. 138- 157.

VVAA, La legislación social en la historia de España. De la Revolución liberal a 1936. Madrid, Congreso de los Diputados, 1987. 